\title{
A Violência Contra Mulher no Cotidiano dos Serviços de Saúde: desafios para a formação médica'
}

\section{Violence Against Women in the Daily Routine of the Health Services: challenges for medical education}

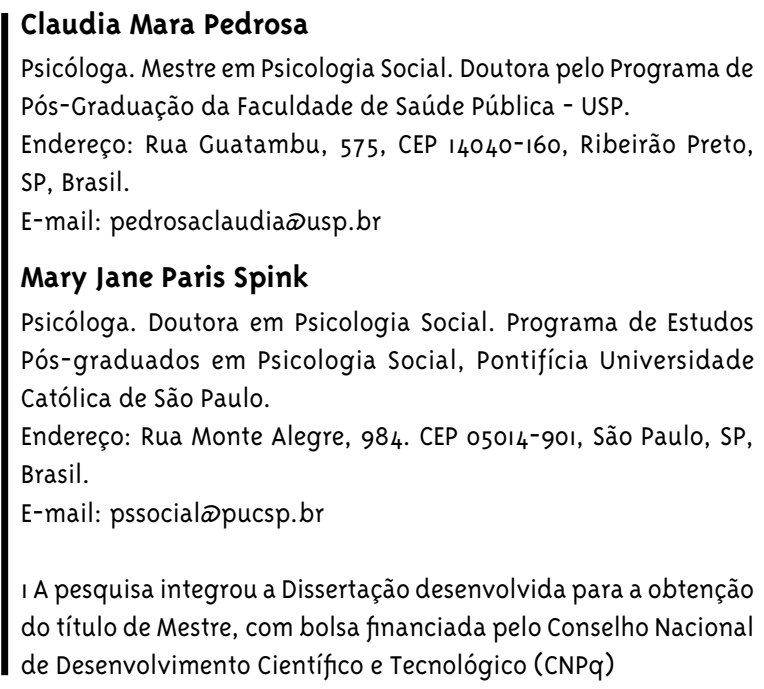

\section{Resumo}

A oferta de atendimento humanizado às mulheres que passaram por situações de violência nos serviços de saúde ainda é um desafio em todos os níveis de atenção. Este artigo discute os sentidos da violência contra mulheres presentes nos discursos dos profissionais médicos, e tem como base teórica a abordagem das práticas discursivas no referencial construcionista da psicologia social. Foram realizadas quatro entrevistas com profissionais de Medicina que atuam em um hospital universitário do interior de São Paulo, e as análises nos possibilitaram constatar as lacunas na formação e nas práticas médica acerca da temática violência de gênero. Concluímos que é preciso propiciar espaços para capacitação, reflexão e suporte ao profissional para que ele se sinta apto e seguro para trabalhar com a questão. As mudanças pedagógicas nos currículos do ensino médico são estratégias significativas para o enfrentamento da violência nos serviços, por demandar transformação das concepções e práticas dos profissionais, ainda muito centradas no enfoque biomédico.

Palavras-chave: Violência contra a Mulher; Educação Médica; Psicologia Social; Construcionismo Social. 


\section{Abstract}

The provision of humane care for women who have undergone situations of violence in the health services is still a challenge at all levels of care. This article discusses the meanings of violence against women in discourses of medical professionals. Its theoretical basis is the discursive practices approach in the constructionist framework of social psychology. Four interviews were conducted with medical professionals who work in a university hospital in the city of Ribeirão Preto, state of São Paulo, and the analysis enabled us to note gaps in medical training and practice on the theme of gender violence. We conclude that we must provide space for professionals' training, reflection and support so that they feel safe and able to work with the issue. The educational changes in medical education curricula are important strategies for coping with violence in the services, as they demand the transformation of the professionals' concepts and practices, which are still based on the biomedical focus.

Keywords: Violence Against Women; Medical Education; Social Psychology; Social Constructionism.

\section{Introdução}

Os serviços de saúde de alta e média complexidade recebem diariamente casos como de Ruth e Marta², que relataram suas experiências em um serviço de psicologia do Sistema Único de Saúde (SUS):

Ruth acordou em um Serviço de Emergência, após tentativa de suicídio por ingestão abusiva de remédios. À equipe que a atendeu explicou, lentamente, o que havia acontecido, e chorando, ela reafirmava que não queria ter sido acudida. Os profissionais prescreveram medicamentos e orientaram a família, a necessidade de Ruth procurar o Posto de Saúde mais próximo de sua residência para iniciar psicoterapia e auxiliar no quadro depressivo. O marido de Ruth observou o papel, confirmou a orientação médica. Ao chegar a casa, olhou para ela e complementou: "nem pra morrer, você presta".

No Ambulatório da Neurologia, Marta, aguardava a realização de uma tomografia computadorizada. Os médicos suspeitavam de tumor, frente aos sintomas recorrentes de cefaleia, perda da coordenação motora e da audição. Enquanto a enfermeira preenchia os papéis, ela suspirava e decidia se contaria que o companheiro a espancava na cabeça. Resolveu que ainda não seria o momento e entrou para o exame.

Os agravos à saúde, causados pela violência, são queixas frequente nos serviços de saúde, em todos os níveis de atenção, e raramente são reconhecidos e abordados como tal. Nos serviços de emergência, a violência conjugal é a maior causa de lesão corporal, sobrepondo-se a acidentes de trânsito; porém, as dimensões que acompanham esse sofrimento marcado no corpo não são consideradas nas condutas médicas (Stark e Flitcraft, 1996). O trabalho médico, como apontou D’Oliveira (1996), devido ao seu aparato conceitual e técnico, reduz o problema da violência a uma questão do corpo individual e o mesmo diagnóstico e conduta serão prescritos tanto à mulher que sofreu uma fratura por acidente de automóvel quanto àquela que apresentou uma fratura por espancamento; os dois corpos assim tratados retornarão à mesma vida social em que se feriram.

2 Nomes fictícios. 
A especialização do saber e das práticas tende a facilitar o distanciamento dos médicos em relação aos usuários do serviço que passam a ser vistos não como seres humanos, mas como um conjunto de células, órgãos e funções fisiológicas, desconectados de sua classe social (Aragaki e Spink, 2009). A preocupação com a formação em saúde tem impulsionado processos de mudança curricular na educação médica, que propõem a formação de profissionais capazes de prestar atenção integral e humanizada às pessoas, e saibam tomar decisões considerando o contexto em que vivem os pacientes, as medidas mais eficazes e os recursos disponíveis (Feuerwerker, 2002).

A abordagem da violência de gênero nos serviços de saúde demanda práticas congruentes com essa perspectiva, em que o profissional se posiciona como facilitador do processo terapêutico, construindo estratégias com as usuárias que contemplem e respeitem seu contexto social e suas singularidades. Para isso, é necessário se aproximar dessas realidades e dar visibilidade aos conflitos que estão subentendidos nas queixas. Ao buscarmos neste artigo compreender a construção das práticas médicas voltadas às mulheres em situação de violência, esperamos contribuir para a inclusão da temática na formação médica e com a discussão da mudança curricular, que objetiva formar profissionais críticos, com capacidade de reflexão acerca das questões sociais, como as desigualdades de gênero.

\section{Violência contra Mulher no Cotidiano dos Serviços de Saúde}

A Organização Mundial da Saúde (OMS) há tempos vem proclamando a necessidade de preparar os profissionais de saúde para o enfrentamento da violência contra a mulher, pois os dados comprovam que a questão está sendo subnotificada, ocultada ou não documentada (OPAS, 1998). Assim, quando a mulher procura o setor saúde, essa busca pode ser considerada um sinal de alerta que precisa ser acolhido. Estudos como de Schraiber e D'Oliveira (1999) apresentam as dificuldades que mulheres em situação de violência têm em procurar ajuda.

A relação da violência com diversos problemas de saúde física, reprodutiva e mental, assim como ao maior uso dos serviços de saúde por parte des- sas mulheres, é uma evidência descrita em vários estudos (Giffin, 1994; D'Oliveira, 2000; Deslandes e col., 2000; Schraiber e col., 2002), o que acentua a necessidade de refletir sobre como o setor tem se organizado para lidar com mulheres em situação de violência.

O Programa de Atenção Integral à Saúde da Mulher (PAISM), formulado no arcabouço do Movimento Sanitário, apesar de representar um avanço e propor uma nova leitura aos agravos à saúde da mulher como fator agravante das iniquidades sociais, não incorporou de imediato, em suas diretrizes, a violência. O PAISM se voltou inicialmente para a reprodução humana, fazendo a crítica ao lugar das mulheres nas práticas na Saúde (Scraiber e col., 2009), assim, a violência contra a mulher no setor Saúde emerge relacionada primeiramente com a prática do aborto legal, o que muitas vezes produz sentidos à violência associados à violência sexual por desconhecidos, não dando visibilidade à violência sexual nas relações com os parceiros íntimos.

Bandeira e Almeida (2008) ao proporem a discussão da invisibilidade das mulheres e da violência contra elas no Sistema Único de Saúde (SUS) ressaltam que, mesmo na especificidade da Medicina voltada à mulher - a Ginecologia -, há uma grande lacuna em relação às problematizações das condições históricas e políticas. 0 conservadorismo com que a saúde da mulher vem sendo abordado está em consonância com as construções sociais do patriarcalismo, ainda muito presente. Para contrapor essa perspectiva, o pensamento feminista contemporâneo tem fomentado a discussão mais focada no sistema de gênero, que perpassa e efetiva o conjunto das relações sociais no campo da saúde. 0 resgate da concepção de conhecimento e "reapropriação" do próprio corpo às mulheres também está presente na pauta do pensamento feminista.

A abordagem oferecida à mulher no serviço de saúde, principalmente na atenção básica, possibilitará desdobramentos importantes na construção das estratégias de enfrentamento à situação de violência vivida. Essas estratégias auxiliarão na transformação do quadro, reduzindo ou eliminando a vulnerabilidade à violência e promovendo a saúde e os direitos de cidadania. Assim, quando as mulheres chegam ao hospital para tratarem sequelas 
ou investigarem sintomas decorrentes de violência crônica, que geralmente ocorre tendo como autor da agressão um parceiro íntimo, podemos problematizar dois importantes aspectos: a gravidade do quadro de saúde e a invisibilidade dada à questão da violência em outros espaços do setor saúde que, geralmente, as mulheres percorrem antes de chegarem à atenção terciária.

Portanto, pareceu-nos importante tentar entender como os profissionais médicos que atuam na atenção hospitalar estão construindo os sentidos atribuídos à violência, já que consideramos que serão esses que orientarão as ações.

\section{Metodologia}

Para entender os sentidos atribuídos à violência contra a mulher, foram realizadas, num hospital público de Ribeirão Preto, 12 entrevistas com profissionais de diferentes áreas da saúde, como enfermagem, serviço social, medicina, psicologia e técnico em enfermagem (Pedrosa, 2003). Neste estudo, devido ao interesse em promover uma discussão mais específica na área da atuação médica, foram analisadas quatro entrevistas de dois médicos residentes em ginecologia e obstetrícia e de dois alunos do último ano do curso de medicina que já cursavam o internato, de ambos os sexos nas duas modalidades. 0 internato é, nos currículos tradicionais de medicina, a fase final do curso médico; nessa fase, não há mais aulas teóricas e os internos fazem estágios em áreas específicas, como clinica médica, ginecologia e obstetrícia, pediatria, cirurgia e saúde coletiva. A eleição de interlocutores da área de ginecologia e obstetrícia, para realizar as entrevistas, se deu pelo contato prévio com o chefe de departamento da área, que se dispôs a auxiliar no contato com os profissionais.

A pesquisa foi submetida ao Comitê de Ética em Pesquisa do hospital, considerando os itens do protocolo padrão do Conselho Nacional de Saúde. As entrevistas foram precedidas pelos esclarecimentos sobre os objetivos da pesquisa e os usos que seriam feitos dos dados, além da leitura e assinatura do Consentimento Informado. Foi enfatizado o caráter voluntário da entrevista e firmado o compromisso de sigilo e respeito à privacidade e à autonomia.

\section{Referencial Teórico}

O referencial teórico da psicologia social, crítica de cunho construcionista, utilizado neste estudo considera que o conhecimento é produzido a partir das interações humanas historicamente situadas, ou seja, é construído conjuntamente pelos atores envolvidos no processo. Assim, podemos afirmar que o interesse central da pesquisa construcionista é o processo de co-construção de sentidos, bem como as ações dele decorrentes. Essa leitura tem sido desenvolvida na abordagem centrada na produção de sentidos e práticas discursivas no cotidiano (Spink, 1999), embasada no construcionismo social (Gergen, 1985; Ibáñez, 1994). A abordagem construcionista, segundo Ibáñez (1994), apresenta-se como uma postura fortemente desreificante, desnaturalizante e desessencializante, que radicaliza ao máximo tanto a natureza social do nosso mundo quanto a historicidade de nossas práticas e de nossa existência. Assim, o que conta como verdade em uma determinada formação social deve ser entendida como produção humana e, portanto, relativa a determinado contexto. Não há uma verdade universal, transcendental e absoluta. Para Ibañez, as verdades não são mais que cristalizações temporárias de conhecimentos, uma vez que as tomamos como produções instáveis, turbulentas, contínuas, que dialogam com saberes instituídos e os questionam (Ibáñez, 1994; Domènech e Ibáñez, 1998).

Nesse enquadre, o conhecimento, seja no âmbito de produção da ciência, seja no cotidiano profissional, é tomado como prática social, deixando de ser atribuído a uma determinada pessoa ou instituição. A construção do saber, sua reprodução e transformação ocorrem por meio de processos intersubjetivos, abandonando-se a ideia de mente individual como produtora de conhecimento (Domènech e Ibáñez, 1998; Ibáñez, 1994; Gergen, 1994). Os conhecimentos são produzidos na interação humana e são fruto da intersubjetividade e, como tal, ancoram os sentidos possíveis das ações cotidianas.

Partimos, portanto, do pressuposto que o acolhimento possível, nos serviços de saúde, da experiência da violência contra a mulher depende de como os profissionais atribuem sentidos à violência quando a pessoa envolvida é uma mulher, e como estruturam suas práticas para seu acolhimento. 
As entrevistas dos profissionais possibilitaram conhecer a co-construção de sentidos, pois as consideramos práticas discursivas, ou seja, são linguagens em ação, por meio das quais as pessoas produzem sentidos e se posicionam em diferentes relações sociais (Spink e Medrado, 1999).

\section{Procedimentos}

Para a análise das entrevistas, utilizamos o método de análise dialógica proposto por Spink (1999), que busca explorar a polissemia do discurso. Para Potter e Wetherell (1987, p. 206) o "Discurso é tratado como um potente meio orientado pela ação e não um canal transparente de informação." É por considerar que o discurso não é transparente que necessitamos de um método de análise que nos possibilite acessar as vias de construção dialógica das falas que constituem o foco do estudo. Os passos da análise seguiram as propostas de Iñiguez e Antaki (1994), que recomendam a leitura do material buscando verificar como ele pode contribuir para a construção de um fato; posteriormente foram construídos mapas dialógicos para os quais foram transcritas as entrevistas na íntegra, respeitando-se a ordem em que os conteúdos aparecem no discurso e enquadrando-os nessas dimensões. Nos mapas, é possível visualizar a associação de ideias entre as dimensões e também as múltiplas ideias e imagens que se fazem presentes em dada dimensão. Finalmente, buscamos no material, analisar outros dados que confirmem as proposições/interpretações feitas.

\section{Resultados}

\section{O Distanciamento da Temática Violência nas Gra- des Curriculares}

A inclusão da temática violência na estrutura curricular do curso de Medicina ainda surge de forma incipiente e superficial. Os profissionais relataram que, durante a formação, entraram em contato com essa temática apenas quando discutiram o atendimento a crianças e adolescente vítimas de violência e quando abordaram a violência sexual. Porém, o enquadre dado a essa discussão, segundo os entrevistados, não abordou questões transversais da violência, como gênero, raça/etnia e classe social. Nas disciplinas propedêuticas, essas questões não são inseridas em uma discussão político-social, estando ainda centradas na abordagem saúdedoença-conduta.

A falta de preparação na formação acadêmica para esse tipo de atendimento se traduz em falta de preparo profissional para a atuação no SUS, ou seja, os profissionais percebem que ainda não conseguem trabalhar em uma perspectiva inclusiva, emancipatória e intersetorial. Quando falam da rede de referência social, que poderá acolher as pessoas em situação de violência após o atendimento hospitalar, tendem a delegar essa orientação aos profissionais da área de assistência social. Dessa maneira, a prática profissional se insere em uma linha descontínua de cuidado em que a usuária é atendida por varias categorias profissionais desconectadas. A fragmentação da organização do trabalho instaura um modelo verticalizado em que cada categoria e cada especialidade criam seu modo de atuar, decorrendo daí etapas de cuidados.

Os profissionais citaram que, na prática, percebem que as queixas das mulheres não são associadas às vivências da violência, principalmente a violência doméstica. Como mencionado anteriormente, sabemos que, sobretudo na atenção terciária, os casos de violência doméstica aparecem quando seus agravos já deixaram sequelas à saúde, sendo mais frequente e visível a entrada de vítimas de violência sexual por autor desconhecido, uma vez que necessitam receber as profilaxias para doenças sexualmente transmissíveis, hepatite e aids e, no caso de mulheres em idade fértil, prevenção à gravidez indesejada ou realização do aborto legal.

Assim, sem um respaldo teórico para o enfrentamento da violência, os profissionais vão associando algumas queixas a situações de sofrimento e opressões de gênero e em determinadas situações, de acordo com a disponibilidade inter-relacional do profissional que está abordando a problemática. Por exemplo, um médico residente relata como a violência perpassa os atendimentos:

Na minha experiência, aqui no hospital, na maioria das vezes não chega diretamente para a gente casos de violência contra mulher. Às vezes, durante uma consulta, você acaba vendo algumas coisas e pergunta. Aí ela explicita. Mas dificilmente, fora isso, ela vai ao serviço para 
isso; não vem consultar para falar da violência (Médico).

A complicação que essa noção traz para o atendimento é que, como a violência não é a queixa principal, se não for atendida não gera problemas, desde que a queixa principal seja atendida e tratada. Não ocorre a fusão entre os determinantes sociais da saúde e o adoecimento; a fala do médico corrobora a dificuldade dos profissionais em falar com as mulheres sobre a vivência da violência.

Os desconhecimentos acerca do manejo da situação vão se materializando na instituição, inicialmente na ausência de discussão curricular e posteriormente na dificuldade de a equipe incluir o tema na investigação e na ausência de um suporte ao profissional.

A gente aprende atendendo; a preparação é a prática mesmo... Acho que é ao longo da experiência mesmo que a gente aprende a atender... geralmente, não tem um preparo mesmo para lidar com essa situação, para abordagem assim... você que cria (Aluno).

Em algumas situações a equipe se aproxima de casos que desvelam a violência, mas o fato não é abordado na perspectiva integral de saúde, pois se limita a determinados setores. Dessa forma, o cuidado novamente se volta para os "problemas de doenças" e os problemas sociais não são vinculados ao projeto terapêutico, como citado na fala abaixo:

Eu vi um caso de uma senhora... uma senhora de 3 o e poucos anos; ela tinha umas escoriações no braço. Mas já se sabia que era uma paciente que tinha problemas; inclusive ela se negava a procurar auxílio de polícia. $E$ o marido era alcoólatra, às vezes batia nela... neste dia ela estava fazendo seguimento na cirurgia vascular. Estava com problemas vasculares, e ela chegou cheia de machucados nos braços e ela não falava nada. Mas se sabia que ela tinha problemas com o marido... Já tinha sido investigado, principalmente pelo pessoal da psicologia, da assistência social. Já se falava em equipe, mas com os médicos ela não falava nada não (Médico).

A violência emerge como questão complexa, de difícil entendimento, principalmente quando está relacionada com as relações afetivas dos casais. Sem um embasamento teórico acerca da construção social dos papéis de gênero e da noção ampliada de cuidados, essa complexidade assume proporções que trazem a sensação de impotência e não resolutividade.

\section{Uso de Protocolos e a Visibilidade da Violência Sexual nas Práticas Médicas}

Os efeitos da violência sexual sobre a saúde podem ser prolongados e crônicos exigindo tratamento e apoio apropriados, tanto pela equipe de saúde quanto pela família e amigos. Problemas como o estresse pós-traumático, que muitas vezes é caracterizado por sintomas como insônia, pesadelos, falta de concentração e irritabilidade, podem permanecer semanas ou meses após a agressão, assim como as dores no baixo ventre ou infecções e transtornos digestivos, como falta de apetite, náusea, vômito, cólica e dor no estômago. Agravos como as doenças sexualmente transmissíveis (DST/aids), infecções urinárias e vaginais, e gravidez são consequências que também podem se manifestar posteriormente (Heise e col., 1994).

Por todas essas razões, a necessidade de oferecer atendimento integral que, além das profilaxias, consiga acolher e respeitar a singularidade de cada mulher possibilita o inicio da reconstrução do impacto vivido.

A mais citada, como evidente na prática médica, foi a violência sexual, em que o autor da agressão é geralmente um desconhecido, um estranho. Os profissionais descreveram a forma como os casos chegam ao serviço e todas as condutas utilizadas, uma vez que o serviço está identificado na região como referência a esse tipo de urgência. Essas condutas são norteadas pelo Protocolo de Atendimento Terciário às Pessoas Vítimas de Agressão Sexual: Estupro e/ou sexo anal, Abuso Sexual e Sexo Anal, do Ministério da Saúde (Brasil, 2005), que foi inserido nas práticas desse hospital desde 2001.

Os profissionais disseram que a utilização do protocolo tem uma importância indiscutível na indicação da medicação e no fluxo interno hospitalar, como, por exemplo, o encaminhamento da mulher, após ser atendida na urgência, para o ambulatório de moléstias infecciosas. Porém, os profissionais também apontaram que, da forma como o atendimento está estruturado, não há espaços para a discussão intersetorial; não há a preocupação com o conforto da usuária dentro do hospital, e não se contempla 
a necessidade de escuta e apoio aos profissionais de saúde que, muitas vezes, sentem o impacto emocional diante do caso, como podemos ver nas duas falas abaixo:

A gente não está muito preparado; para mim é um atendimento muito difícil. Não acho que estou preparado. Tenho muita dificuldade para abordar, como perguntar. Sabe, detalhes, se eu devo perguntar, se não vai ser pior para ela... (Aluno)

A equipe toda, aliás, todos os profissionais da Emergência, desde a portaria, não estão preparados. Eu até estava comentando com o Dr. $X$ que paciente vitimizada vira uma atração. A ficha [para casos de agressão sexual], se eu deixar ela lá em cima, todo mundo vai lá ler, fica comentando... eu carrego a ficha comigo até o fim do plantão... não largo mesmo! (Médica)

A organização do trabalho, segundo os profissionais, não contribui para o aprimoramento dos atendimentos, pois as sobrecargas, associadas às dificuldades pessoais dos profissionais, podem anular a intenção da aplicação de um protocolo efetivo que, além das condutas das profilaxias, humanize as práticas. A fala da médica ilustra essa realidade:

Até assim a gente você vê que nós não temos preparo nenhum. Vocêvai aprendendo de olhos fechados, na prática mesmo, é assim com todos os profissionais que estão aqui... elas são atendidas muitas vezes por residentes que têm mil coisas para fazer... Por exemplo, eu acompanhei uma vez um caso que a pessoa tinha sido violentadae tinha um ferimento importante na região vaginal, e a princípio ela não queria receber atendimento. Ela veio até aqui, mas ela não queria ser cuidada. $\varepsilon$ até essa mulher aceitar receber o atendimento a gente teve assim um trabalho exaustivo... Mas, por exemplo, a médica que estava atendendo perdeu a paciência, disse assim: "se você não quer problema seu, você que vai ficar infectada, você que vai ficar doente, você pode até morrer... problema seu, eu não vou te atender mais" e tirou as luvas, jogou e saiu... e não tem mesmo preparo nenhum, e aí de novo foi uma violência, porque foi uma situação muito agressiva para ela. A equipe não estava tendo condições de esperar a condição emocional dela (Médica).

\section{Violências Silenciadas: percepções de outras for- mas de desigualdades de gênero}

Outras formas de violência aparecem no cotidiano hospitalar de maneira mais discreta, às vezes indiretamente, mas nem sempre estão inseridas no âmbito do cuidado, como no caso da violência sexual. Diferentes categorias de violência são identificadas durante a prática segundo os profissionais entrevistados; outras são notadas na prática dos colegas, principalmente a violência institucional. A violência social também foi reconhecida no cotidiano da saúde, porém ela não entra nas anotações dos prontuários. As usuárias entram no serviço, relatam seus sintomas, que estão perpassados pela exclusão social e pela miséria, mas esse aspecto não é enfatizado como determinante social da saúde.

Na descrição dos entrevistados acerca do tratamento as mulheres em situação de violência, os julgamentos dos discentes e docentes da faculdade se fizeram presentes. As expectativas sobre as usuárias parecem ter sido orientadas pelas experiências de vida de cada um e muitas vezes concretizando formas de opressão e violência contra a mulher. A identificação da violência institucional foi bastante marcante, e o cuidado, em vez de cumprir a função social de empoderar e gerar autonomia as mulheres, acaba oprimindo e ressaltando as iniquidades de gênero. Os profissionais assumem uma postura que utiliza o poder do saber, o lugar de legitimação institucional do saber como um modo de relacionar-se com os clientes, ignorando o saber das usuárias.

Essa junção de opressão de saberes e de gênero afasta os profissionais da clientela e não possibilita a compreensão acerca da realidade social e cultural em que essas pessoas estão inseridas. Por exemplo, uma aluna nos conta que os médicos chamam as mães de tigronas, porque as consideram pouco colaboradoras ou ausentes.

A dificuldade de analisar a perspectiva socioeconômica que demarca o mundo dos "doutores" e a sua clientela gera o que Bourdieu (1998) chamou de violência simbólica ${ }^{3}$. Ela está presente nas conversas cotidianas dos profissionais de saúde com os pacientes, nas quais estes impõem seus valores aos clientes. A aluna faz considerações sobre a distância social e emocional entre os profissionais e suas pacientes, como no caso abaixo: 
E essa semana teve uma [mãe] que o marido, o pai da criança, tinha sido preso um dia antes de ela ter a criança... e a gente chegou para ver o bebê, que começou a chorar... Estávamos em doze estudantes de medicina, mais o professor, mais três residentes de medicina, mais enfermeira; tudo no quarto. Quando chegou o professor, ele sempre chega do mesmo jeito: "e aí mãe, você é fulana de tal, esse é o campeão? Como é o nome dele?”. E ela respondeu que não tinha nome. Ele insistiu para saber se tinha passado os nove meses achando que era menina, por isso que não escolheu o nome. Mas aí ela disse que não: "a gente ainda não escolheu o nome, quem vai escolher é o pai" E ele continuou a perguntar, mas ela não respondia. Você via que a mulher estava em pânico. Eu estava sentada ao lado dela, e você via... sabe quando a mulher... quando a mulher está em pane... sabe assim, quando você olha para ela e é uma pessoa curvada, assustada, não olha no seu olho... uma coisa corporal uma expressão corporal... uma expressão oprimida... (Aluna)

O professor ignorou a história de vida da mulher, que fazia toda a diferença no contexto. Assim, para se efetivar um modelo de atenção integral na assistência hospitalar é preciso visualizar a clientela como sujeitos ativos, em sua singularidade, e prezar pelo respeito dentro do espaço de cuidado.

0 atendimento realizado de maneira mecânica, sem vínculo, afeto e respeito pelo outro presente na relação de cuidado, pode se configurar uma violência institucional, em que, muitas vezes, o poder técnico do profissional oprime o direito da usuária. A aluna faz apontamentos críticos ao descrever o excesso de intervenções às parturientes, como medicação e toque, além dos altos índices de cesarianas, principalmente nos plantões noturnos; opção mais favorável aos médicos.

Essas condutas revelam a dimensão da violência institucional e da naturalização da violência nos procedimentos médicos. Apesar de todas as con- quistas dos movimentos feministas ao longo dos anos, as mulheres continuam a ser tratadas pelos médicos apenas como corpos. Discutir na graduação de Medicina noções de gênero, direitos reprodutivos e humanos é fundamental para nortear os posicionamentos e as práticas dos futuros profissionais. 0 distanciamento da academia das questões políticas e sociais tem apresentado ações descoladas da realidade brasileira.

Quando analisamos a ausência dos temas em questão: violência e gênero nos currículos de formação nas práticas de saúde, não podemos reduzir essa lacuna à falta de discussão teórica, pois as estudantes e as profissionais estão observando ou vivenciando as situações em seu entorno, estão inseridas em uma rede em que as instituições e suas políticas no dia a dia não permitem relações horizontais de gênero. Parece que há um pacto de silêncio entre os profissionais de saúde, que contribui para a anulação da equidade de gênero em todos os âmbitos da sociedade.

\section{A Violência e o Impacto Emocional no Cotidiano Médico}

A mobilização emocional diante do atendimento da violência desencadeia uma multiplicidade de sentimentos e raramente as instituições conseguem oferecer acolhimento adequado aos cuidadores, deixando consequências importantes na rotina de trabalho. Podemos ver, nas seguintes falas, como os profissionais tentam buscar seus próprios recursos para lidar com a situação e como sentem a equipe vivenciando esses impactos:

Porque é pesado [o atendimento]... sabe na sextafeira eu atendi dois casos [de estupro], e eram pessoas mais próximas... alunas da universidade; são realidades parecidas com a nossa. Então a gente se envolveu muito com o caso. Eu atépeguei o número do meu telefone e falei, oh, tá aqui, se pegar o cara, liga pra mim avisando... me liga pra contar [diz emocionada]. (Médica)

\footnotetext{
3 A violência simbólica, segundo Bourdieu (1998, p. 47), "se institui por intermédio da adesão que o dominado não pode deixar de conceber ao dominador [portanto à dominação], uma vez que ele não dispõe para pensá-la ou para si pensar, ou melhor, para pensar sua relação com ele, mais que de instrumentos de conhecimento que ambos têm em comum e que, não sendo mais do que a forma incorporada da relação de dominação, mostram esta relação como natural; ou, em outros termos, que os esquemas que ele mobiliza para se perceber e se avaliar ou para perceber e avaliar o dominador são produtos da incorporação de classificações, assim naturalizadas, das quais seu ser social é o produto.".
} 
A mobilização emocional pode desencadear varias estratégias de atuação, em alguns momentos, angustia e distanciamento dos profissionais e, em outros, sensibilização e atitude solidária. A identificação dos profissionais com as pessoas em situações de violência, quando o fato ocorrido remete a riscos aos quais qualquer um poderia estar exposto parece gerar curiosidade e se busca entender a situação ou acolher a vítima e seus familiares. Novamente, percebemos que a violência sexual cometida por um desconhecido é a que mais aparece como fator desencadeante desses sentimentos.

Um caso que marcou foi de uma moça, garota de programa, grávida e usuária de crack... e foi violentada - um cara ofereceu a ela droga... ela foi à casa dele... e aí ele a agrediu fisicamente, estuprou sob ameaça... Muito deprimente. Ela magrinha, debilitada, desnutrida, chorando muito. E falava que não queria mais usar droga, mas, não conseguia... Você fica pensando na vida da pessoa né? é difícil... (Médico)

Os casos que envolvem miséria e vulnerabilidade social parecem criar, na equipe, o sentimento de impotência, tristeza e comoção. São realidades sociais que impactam pela magnitude da exclusão, abandono e fragilidade.

As ações de saúde devem ser pensadas na dialogia profissional-usuário, pois o médico também precisa ser cuidado por meio de supervisões e grupos de reflexão, a fim de ter uma válvula de escape ao estresse emocional. Esses espaços são relevantes na avaliação dos profissionais que participaram do estudo, porque ajudam na preparação para atendimentos complexos, como aqueles, em que a violência é marcante.

\section{Discussão}

A análise das entrevistas nos possibilitou constatar a multiplicidade de sentidos atribuídos à violência contra a mulher e as dificuldades vivenciadas no cotidiano hospitalar. A forma como o atendimento é oferecido no contexto onde foram realizadas as entrevistas configura-se como aquele voltado à atenção especializada que tende a perder de vista o todo e parece contribuir para dificultar a investigação das questões associadas ao adoecimento relacionado à violência.
Os discursos dos profissionais de saúde estão permeados por tentativas de explicação da violência contra a mulher, que estão baseadas, quase sempre, nas experiências e vivências de cada profissional. Em nenhum momento, nesta pesquisa, eles se referiram a qualquer tipo de orientação especializada quanto às questões de violência de gênero. Os profissionais foram unânimes em afirmar que as discussões acerca de gênero e da violência contra a mulher não fizeram parte de sua formação profissional e estão ausentes dos currículos acadêmicos.

Essa lacuna na formação reflete-se no dia a dia dos profissionais nos serviços de saúde que, muitas vezes, sentem-se inaptos para lidar com as questões associadas à violência doméstica. Sem a capacitação para o enfrentamento da questão e sem ter a quem recorrer nos momentos de dificuldades, os profissionais vão aprendendo a lidar com a complexidade por meio da prática, criando a sua própria maneira de atendimento. Alguns se solidarizam e oferecem acolhimento; outros se distanciam, tratam com aspereza e, às vezes, acabam, sem perceber, maltratando e/ou agredindo as mulheres.

Vale lembrar que a violência tem muitas dimensões e engendra diversos sentidos que se articulam na rede de interlocução no cotidiano das instituições de saúde e dos profissionais. Especificamente no caso da violência contra a mulher, essa rede é atravessada também pelas noções de gênero, de sexualidade, de saúde, de relacionamentos afetivos e pelas emoções a elas associadas. Assim, cada vez que o profissional se depara com a necessidade de viabilizar ações que possam minorar o sofrimento causado pela violência, é essa rede de sentidos que orienta as práticas. Mas, como não há preparo específico para lidar com essas situações, muitas vezes elas têm sobre eles consideráveis impactos emocionais.

Ficou evidente na pesquisa que entrar em contato com a violência produz forte mobilização afetiva nos profissionais, gerando ansiedade, angústia e medo. É necessário, portanto, levar em consideração os fatores emocionais não só dos pacientes, mas também dos profissionais, na elaboração de ações propositivas para lidar com a violência de gênero, oferecendo recursos como supervisões e discussões interdisciplinares. 
Em todos os discursos ficou evidente a necessidade de políticas de atendimento específicas para orientar as práticas nos serviços de saúde. Os atendimentos em casos de violência demandam, segundo os entrevistados, um novo modelo institucional, capaz de oferecer um ambiente mais acolhedor, que facilite a criação do vínculo de confiança entre a usuária e o profissional. A disponibilidade de tempo para o atendimento foi outro fator descrito como facilitador da intervenção, aspecto que pode ser compreendido tendo em vista a mobilização afetiva que tratar e falar da violência ocasiona, assim como a dificuldade da mulher em associar o seu adoecimento à situação de violência que vivencia. 0 modelo de atendimento atual, no serviço público de saúde, na maioria das vezes, não propicia essas condições; é comum encontrar um grande número de pacientes para cada profissional, tornando as consultas rápidas e focadas na doença aparente. Essas condições vêm reforçar as afirmações de Grossi (1994) acerca da rotulação da mulher em diagnósticos baseados apenas nas sintomatologias, aspecto que tem contribuído para o ocultamento da violência doméstica.

A implantação do atendimento integrado, que possibilita os profissionais de saúde de diferentes formações acadêmicas estabelecer estratégias conjuntas, e as articulações com a rede social de suporte visam oferecer às usuárias do serviço um melhor acolhimento que não fica restrito a ações focais de caráter curativo (Feuerwerker, 2002). Entretanto, o que se observa hoje é a hegemonia biomédica que parece contribuir para reduzir a paciente a seu sintoma, dispensando o olhar para os fatores que perpassam a situação de violência.

É necessário ressaltar a importância de a equipe interdisciplinar investir nas discussões dos casos atendidos, utilizando para essa reflexão os sentidos pessoais acerca da violência contra a mulher e a maneira como eles se constroem na interação do atendimento. Outro aspecto que chamou atenção nesta pesquisa foi a presença de diferentes modalidades de violência no âmbito da própria instituição, especialmente na relação profissional de saúde-usuária. O lugar do saber do profissional pode, em algumas circunstâncias, ser transformado no lugar de poder para oprimir e excluir.

\section{Conclusões}

É preciso transformar as relações desiguais de poder para que o profissional possa se aproximar das usuárias e auxiliá-las a romper o ciclo de violência em que estão imersas. A educação para a cidadania que produz mudanças culturais, segundo Ávila (2002), é um trabalho fundamental para criar sustentabilidade democrática nos processos de desenvolvimento da cidadania e na construção de sujeitos políticos que atuem na esfera pública. Ávila ressalta que o processo da aprendizagem sobre direitos guarda duas dimensões, a do conhecimento dos direitos e a da construção para o seu uso.

Para os profissionais poderem ocupar a posição de facilitadores, da transformação da situação que a mulher vive, é necessário criar espaços para que possam refletir e explicitar de que forma as questões de gênero e de violência foram significadas dentro de determinado contexto sócio-histórico e cultural (Pedrosa, 2009), ou seja, é difícil propor um tratamento humanizado e integral se este ficar descolado da discussão crítica do contexto psicossocial em que estão inseridas as usuárias dos serviços de saúde.

A transformação das políticas, dos serviços e das práticas passa pela incorporação do conhecimento do outro a quem se destina a ação que busca trazer o local, a singularidade e as particularidades, promovendo a conexão de múltiplos saberes, os científicos e os populares. O conjunto de sentidos da integralidade, que se espera incidir sobre as práticas dos profissionais, tem como foco a necessidade de discernir de modo abrangente as necessidades das(os) usuárias(os) (Pinheiro e Mattos, 2001). No caso desta pesquisa, poderíamos ressaltar que o atendimento às mulheres em situação de violência no âmbito hospitalar demanda a transformação da política verticalizada, que estanca o cuidado em um programa específico, desarticulado de outras possibilidades. Se a mulher é admitida para um tratamento ginecológico, esse cuidado se limita a essa especialidade que, por sua vez, não se comunica com os serviços primários e secundários que a acolherão após a internação ou a atenção especializada.

O desamparo que segue a(o) profissional após o atendimento da violência gerando impactos emocionais e dificuldades de diversas ordens não encon- 
tram espaços para o acolhimento entre seus pares, não é estruturado na lógica institucional o espaço de cuidado ao cuidador, "abandonando-as(os)" à reestruturação emocional solitária. Essas invisibilidades negam a integralidade na organização dos serviços, para quem atua e para quem é assistido.

Portanto, podemos concluir que a ausência da integralidade como princípio orientador da formação profissional, das práticas, da organização do trabalho e das políticas impossibilita também a questão do enfrentamento da violência de gênero, ações resolutivas e empoderadoras, que possibilitariam novos rumos e respostas mais amplas às mulheres. A limitação do adoecer em sua enfermidade nega o sujeito nessa relação, inserindo-a(o) novamente em um lugar social de negação e dominação.

É importante pensar esses atendimentos como uma ordem negociada, como discute Spink (2003), o que implica dar voz às visões de mundo do interlocutor, dialogando com os repertórios que a parte dominada (o paciente, especialmente se membro das classes populares) dispõe para pensar e falar de sua condição.

Possibilitar a abertura da discussão de violência no âmbito dos serviços da saúde é viabilizar a promoção dos direitos da mulher e estabelecer relações horizontais de gênero. Para isso, é preciso propiciar espaços para refletir sobre a atuação dos profissionais e seus posicionamentos dentro da instituição, além de fornecer meios de capacitação, incluindo a inserção nos currículos da área da saúde de temáticas que atravessam o adoecimento, como questões racial-étnicas, de gênero e classe social.

\section{Referências}

ARAGAKI, S. S.; SPINK, M. J. P. Os lugares da psicologia na educação médica. Interface: comunicação, saúde, educação, Botucatu, v. 13, n. 28, p.85-98, jan./mar. 2009.

ÁVILA M. B.; Cidadania, direitos humanos e direitos das mulheres In: BRUSCHINI, C.; UNBEHAUM, S. (org.) Gênero, democracia e sociedade brasileira. São Paulo: FCC,Editora 34, 2002. p. 121-142.
BANDEIRA, L.; ALMEIDA, T. M. C. Desafios das políticas e ações em saúde diante da violência contra as mulheres, SER Social, Brasília, v. 10, n. 22, p. 183-212, jan./jun. 2008.

BOURDIEU, Pierre. A dominação masculina. Rio de Janeiro: Bertrand Brasil. 1998.

BRASIL. Ministério da Saúde. Secretaria de Atenção à Saúde. Departamento de Ações Programáticas Estratégicas. Prevenção e tratamento dos agravos resultantes da violência sexual contra mulheres e adolescentes: norma técnica. Brasília: Ministério da Saúde, 2005. 68 p. Disponível em: <http://campanhapontofinal.com. br/download/informativo_o1.pdf> . Acesso em: 15 mar. 2003.

DESLANDES, S. F.; GOMES, R.; SILVA, C. M. F. P. Caracterização dos casos de violência doméstica contra a mulher atendidos em dois hospitais públicos do Rio de Janeiro. Cadernos de Saúde Publica, Rio de Janeiro, v.16, n.1, p.129-37, jan./mar. 2000.

DOMÈNECH, M.; IBÁÑEZ, T. La Psicologia Social como crítica. Anthropos: Psicología Social. Una visión crítica e histórica, Barcelona n. 177, p. 13-21, 1998.

D'OLIVEIRA, A. F. P. L. Gênero e violência nas práticas de saúde: contribuição ao estudo da atenção integral à saúde da mulher. 1996. Dissertação (Mestrado em Medicina Preventiva)Faculdade de Medicina, Universidade de São Paulo, São Paulo, 1996.

D'OLIVEIRA, A. F. P. L. Violência de gênero, necessidade de saúde e usos de serviços em atenção primária. 200o. 279 f. Tese (Doutorado em Medicina Preventiva)- Faculdade de Medicina, Universidade de São Paulo, São Paulo, 2000.

FEUERWERKER, L. C. M. Mudança na educação médica: os casos de Londrina e Marília. São Paulo: Hucitec, 2002.

GERGEN, K. J. The social constructionist movement in modern psychology. American Psychologist, Washington, D.C. v. 40, n. 3, p. 266 275, mar. 1985 . 
GERGEN, K. El puento muerto del conocimiento individual. In: GERGEN, K. Realidades y relaciones: aproximaciones a la construcción social. Barcelona: Paidos, 1994, p. 89-123.

GROSSI, M. P. Novas/Velhas violências contra a Mulher no Brasil. Estudos Feministas, Florianópolis, n. Especial Colóquio Internacional Brasil, França e Quebec, p. 473-483, jul.-dez. 1994.

GIFFIN, K. Violência de gênero, sexualidade e saúde. Cadernos de Saúde Pública, Rio de Janeiro, v. 10, supl. 1, p. 146-155, 1994.

HEISE, L. et al. Violence against women: the hidden health burden. Washington, D. C.: The international Bank for Reconstruction and Development, The World Bank, 1994.

IBÁÑEZ, T. La psicología social como dispositivo desconstruccionista. In: IBAÑEZ, T. Psicología social construccionista. Guadalajara, México: Universidad de Guadalajara, 217-243. 1994.

IÑIGUEZ, L.; ANTAKI, C. El analisis del discurso em psicología social. Boletim de Psicologia, São Paulo, v. 44, p. 55-75, 1994.

ORGANIZACION PANAMERICANA DE LA SALUD - OPAS. Violencia contra la mulher: un tema de salud prioritario. Washington, D.C.: Division de Salud Familiar y Reproductiva; Division de Salud y Desarrollo Humano, 1998.

PEDROSA, C. M. Mulheres em situação de violência: o discurso dos profissionais de saúde. 2003. 126 f. Dissertação (Mestrado em Psicologia Social)- Pontifícia Universidade Católica de São Paulo, São Paulo, 2003.
PEDROSA, C. M. A construção de uma ferramenta social para promoção da saúde e dos direitos das mulheres. Paidéia, Ribeirão Preto, v. 19, n. 42, p. 123-130, jan./abr. 2009.

PINHEIRO, R.; MATTOS R. A. Os sentidos da integralidade na atenção e no cuidado à saúde. Rio de Janeiro: UERJ-IMS, ABRASCO, 2001.

POTTER, J.; WETHERELL, M. Discourse and social psychology: beyond attitudes and behaviour. London: Sage Publications. 1987

SCHRAIBER, L. B.; D’OLIVEIRA, A. F. P. L.

Violência contra mulheres: interfaces com a saúde. Interface: comunicação, saúde, educação, Botucatu, v. 3, n. 5, p. 11-26, ago. 1999.

SCHRAIBER, L. B. et al. Violência contra a mulher: estudo em uma unidade de atenção primária à saúde. Revista de Saúde Pública, São Paulo, v. 36, n. 4, p. 470-477, ago. 2002.

SPINK, M. J. P. (org.). Práticas discursivas e produção de sentidos no cotidiano: aproximações teóricas e metodológicas. São Paulo: Cortez, 1999.

SPINK, M. J. P.; MEDRADO, B. Produção de sentidos no cotidiano: uma abordagem teórico-metodológica para análise das práticas discursivas. In: SPINK, M. J. P.(org.) Práticas discursivas e produção de sentidos no cotidiano: aproximações teóricas e metodológicas. São Paulo: Cortez, 1999.

SPINK, M. J. P. Psicologia social e saúde: prática, saberes e sentidos. Petrópolis, RJ: Vozes, 2003.

STARK, E.; FLITCRAFT, A. Women at risk: domestic violence and women's health. Sage Publications, Thousand Oaks, 1996. 